\title{
Systolic dysfunction of systemic ventricle in patients who underwent a Fontan operation
}

\author{
Taliha Öner ${ }^{1}$, Şevket Ballı1 ${ }^{1}$, Emine Hekim Yılmaz ${ }^{1}$, Mustafa Orhan Bulut ${ }^{1}$, \\ Ahmet Şaşmazel ${ }^{2}$, Ahmet Çelebi ${ }^{1}$ \\ Departments of ${ }^{1}$ Pediatric Cardiology and ${ }^{2}$ Pediatric Cardiovascular Surgery, Dr. Siyami Ersek Thoracic and Cardiovascular \\ Surgery Training and Research Hospital, İstanbul, Turkey. E-mail: talihaoner@yahoo.com \\ Received: 12th November 2018, Accepted: 5th January 2019
}

SUMMARY: Öner T, Ballı Ş, Hekim Yılmaz E, Bulut MO, Şaşmazel A, Çelebi A. Systolic dysfunction of systemic ventricle in patients who underwent a Fontan operation. Turk J Pediatr 2019; 61: 925-930.

The aim of the study was to report the clinical and echocardiographic data of patients who underwent a Fontan operation, and define the group with systolic dysfunction in the systemic ventricle observed during postoperative follow-up. The medical records of 183 patients [mean age: $10.93 \pm 5.89$ years (range: 2.5-45 years)] who were referred to our center and underwent a Fontan operation were retrospectively reviewed. The clinical, echocardiographic, and postoperative follow-up data of the patients were recorded. Preoperatively, $68(37.2 \%)$ patients experienced pulmonary stenosis, while $41(22.4 \%)$ had pulmonary atresia and $74(40.4 \%)$ had pulmonary hypertension. The most common pathology in patients who were ineligible for biventricular repair was tricuspid atresia, seen in 51 patients $(27.9 \%)$, followed by double-inlet left ventricle pathologies in 40 patients $(21.9 \%)$. In total, $38(20.7 \%)$ patients had a biventricular structure; among those with a single ventricular structure, the systemic ventricle involved was the right ventricle in 51 (27.9\%) patients and the left ventricle in $94(51.4 \%)$ patients. During follow-up, a total of 31 (16.9\%) patients underwent catheterization and ventricular systolic functions were preserved in $168(91.8 \%)$ patients. In Fifteen $(8.2 \%)$ patients developed systolic dysfunction (ejection fraction $<50 \%$ ). The mean age of the group developing systolic dysfunction was $15.6 \pm 2.63$ years (median, 13 years; range: 5-45 years). Of this group, 10 patients had a left ventricular structure of the systemic ventricle, 14 had atrial situs solitus, and 4 had moderate atrioventricular valve insufficiency. Even if the systemic ventricle is in the left ventricular structure, systolic dysfunction in the systemic ventricle develops, especially after the first 10 years, and this makes us think rudimentary ventricle function should also be carefully monitored for intra-univentricular diastolic asynchrony.

Key words: fontan operation, children, ventricular disfunction.

A Fontan operation is a surgical procedure performed to reduce or eliminate cyanosis in patients with a single ventricular physiology. ${ }^{1}$ Usually, a total cavopulmonary connection is performed after an interval of 18-24 months, for which $18-\mathrm{mm}$ conduits are used. A fenestration is formed by leaving a $4-\mathrm{mm}$ opening in the intra-atrial baffle or extracardiac conduit. ${ }^{1}$ Although considered an effective surgical approach, a Fontan operation can lead to late-term problems such as reoperations, re-interventions, tachyarrhythmia, protein-losing enteropathy, ventricular dysfunction, and progressive exercise intolerance. ${ }^{1}$ The presentation of myocardial dysfunction after a Fontan operation can be a cause of heart failure, and the global causes of decreasing ventricular functions include increased systemic vascular resistance after a Fontan operation, improper hypertrophy of the 
left ventricle due to increased mass/volume ratio, high pulmonary vascular resistance, and univentricular anatomy. After excluding anatomical causes, the optimal medical therapy for heart failure remains a matter of debate. ${ }^{2,3}$

\section{Material and Methods}

The medical records of 183 patients (95 males [51.9\%], 88 females [48.1\%]) who were referred to our center and underwent a Fontan operation between July 2002 and December 2017 were retrospectively reviewed.

Data from echocardiography, and applied surgical procedures and catheterizations were recorded. The data are presented as means \pm standard deviation. Median values were additionally used when standard deviations were found to be greater than half the mean value due to large differences between the minimum and maximum values. The study was approved by the ethical committee of Istanbul Dr. Siyami Ersek Thoracic and Cardiovascular Surgery Training and Research Hospital approval study number 28001928-508.01

\section{Results}

Preoperatively, 68 (37.2\%) patients had pulmonary stenosis, 41 (22.4\%) had pulmonary atresia, and $74(40.4 \%)$ had pulmonary hypertension. The most common pathologies in patients who were ineligible for biventricular repair were tricuspid atresia in 51 (27.9\%), double-inlet left ventricle in 40 (21.9\%), unbalanced atrioventricular septal defect in $27(14.8 \%)$, pulmonary atresia with intact ventricular septum in $14(7.7 \%)$, atrioventricular-ventriculoarterial discordance with ventricular septal defect in 11 (6\%), complete transposition of large arteries with ventricular septal defect in $13(7.1 \%)$, double outlet right ventricle - ventricular septal defect in six $(3.3 \%)$, and other types of pathologies (mitral atresia, hypoplastic left heart syndrome, etc.) in $21(11.5 \%)$ patients. Among the entire patient group, $164(89.6 \%)$ had atrial situs solitus and $19(10.4 \%)$ had a right atrial isomerism. In total, $38(20.7 \%)$ patients had a biventricular structure, and among those with a single ventricular structure, the systemic ventricle was the right ventricle in $51(27.9 \%)$ patients and the left in 94 (51.4\%) patients. While fenestration was not noted in $117(63.9 \%)$ patients, in $66(36.1 \%)$ fenestration was open. No atrioventricular valve insufficiency was observed in 117 (63.9\%) patients, while mild and moderate atrioventricular insufficiency was noted in 50 $(27.3 \%)$ and $16(8.8 \%)$ patients, respectively (Table I).

Table I. General Characteristics of All Patients.

\begin{tabular}{|c|c|}
\hline \multicolumn{2}{|l|}{$\mathrm{N}=183$} \\
\hline \multirow{2}{*}{ Gender } & 95 males $(51.9 \%)$ \\
\hline & 88 females $(48.1 \%)$ \\
\hline Age (years) & $10.93 \pm 5.89(2.5-45)$ \\
\hline Pulmonary atresia & $41(22.4 \%)$ \\
\hline Pulmonary stenosis & $68(37.2 \%)$ \\
\hline Pulmonary hypertension & $74(40.4 \%)$ \\
\hline $\begin{array}{l}\text { Systemic ventricle left } \\
\text { ventricle }\end{array}$ & $94(51.4 \%)$ \\
\hline $\begin{array}{l}\text { Systemic ventricle right } \\
\text { ventricle }\end{array}$ & $51(27.9 \%)$ \\
\hline Biventricular morphology & $38(20.7 \%)$ \\
\hline Situs solitus & $164(89.6 \%)$ \\
\hline Right atrial isomerism & $19(10.4 \%)$ \\
\hline Tricuspid atresia & $51(27.9 \%)$ \\
\hline DILV & $40(21.9 \%)$ \\
\hline AVSD (unbalance) & $27(14.8 \%)$ \\
\hline PA-IVS & $14(7.7 \%)$ \\
\hline AV-VA discordance-VSD & $11(6 \%)$ \\
\hline TGA-VSD & $13(7.1 \%)$ \\
\hline DORV-VSD & $6(3.3 \%)$ \\
\hline Other pathologies & $21(11.5 \%)$ \\
\hline Fenestration open & $66(36.1 \%)$ \\
\hline Fenestration closed & $117(63.9 \%)$ \\
\hline No AV valve insufficiency & $117(63.9 \%)$ \\
\hline Mild AV valve insufficiency & $50(27.3 \%)$ \\
\hline $\begin{array}{l}\text { Moderate AV valve } \\
\text { insufficiency }\end{array}$ & $16(8.8 \%)$ \\
\hline
\end{tabular}

DILV, double-inlet left ventricle; AVSD, atrioventricular septal defect; PA-IVS, pulmonary atresia with intact ventricular septum; AV-VA, atrioventricularventriculoarterial; TGA-VSD, transposition of the great arteries-ventricular septal defect; DORV-VSD, double outlet right ventrical-ventricular septal defect. 
During follow-up, ventricular systolic function was preserved in $168(91.8 \%)$ patients, while $15(8.2 \%)$ patients developed systolic dysfunction [ejection fraction $<50 \%$ ]. The mean age of the group developing systolic dysfunction was $15.6 \pm 2.63$ years (median, 13 years; range: $5-45$ years), and this group included seven (46.7\%) male and eight $(53.3 \%)$ female patients. Furthermore, 10 patients had a left ventricular structure of the systemic ventricle, 14 had atrial situs solitus, and 4 had moderate atrioventricular valve insufficiency (Table II).

A total of 31 (16.9\%) patients underwent catheterization during the follow-up period: $12(38.7 \%)$ underwent a fenestration closure, $5(16.1 \%)$ underwent a fenestration opening, 5 (16.1\%) underwent pulmonary artery stenting, 5 (16.1\%) underwent a pulmonary artery stenting plus fenestration closure, $3(9.7 \%)$ underwent a pulmonary artery antegrade closure, and 1 (3.2\%) underwent a pulmonary artery stenting plus antegrade flow closure procedure (Table III). In the group with $\mathrm{saO}_{2}<90 \%$ only, in the absence of a complaint requiring fenestration closure, a fenestration test occlusion was performed with a Fontan operation being carried out in the event of pressure $<18 \mathrm{mmHg}{ }^{4}$ A Fontan operation was performed when the pressure difference demonstrated by echocardiography was less than a mean of $3 \mathrm{mmHg}$, and a balloon/stenting procedure was performed in regions that were observed to be narrowed during catheterization. ${ }^{5}$ A fenestration opening or widening procedure was performed in patients with a Fontan pressure $>18$ mmHg. In total, seven $(3.8 \%)$ and four $(2.2 \%)$ patients were followed for arrhythmia and
Table II. Characteristics of Patients with Systolic Dysfunction.

\begin{tabular}{ll}
\hline & $\begin{array}{l}\text { Patients with } \\
\text { decreased EF (n = 15) } \\
(7.8 \%)\end{array}$ \\
\hline Current age (years) & $\begin{array}{l}15.6 \pm 2.63(5-45) \\
44.73 \pm 8.11(29-50)\end{array}$ \\
EF (\%) & $8(53.3 \%)$ \\
Pulmonary hypertensive & $6(40 \%)$ \\
Pulmonary stenosis & $1(6.7 \%)$ \\
Pulmonary atresia & $93.3 \%$ \\
$\begin{array}{l}\text { Atrial situs solitus } \\
\text { Systemic ventricle left }\end{array}$ & $10(66.6 \%)$ \\
$\begin{array}{l}\text { ventricle } \\
\text { Systemic ventricle right }\end{array}$ & $3(20 \%)$ \\
$\begin{array}{l}\text { ventricle } \\
\text { Aiventricular morphology }\end{array}$ & $2(13.4 \%)$ \\
(modve insufficiency & $4(26.6 \%)$ \\
$\begin{array}{l}\text { AV valve insufficiency } \\
\text { (Mild) }\end{array}$ & $7(46.7 \%)$ \\
$\begin{array}{l}\text { No AV valve insufficiency } \\
\text { catheterization }\end{array}$ & $4(26.6 \%)$ \\
\hline EF, eiection fraction; AV, atrioventional & $5(33.3 \%)$ \\
\hline
\end{tabular}

EF, ejection fraction; $\mathrm{AV}$, atrioventricular.

cranial events, respectively, and seven (3.8\%) patients underwent anti-pulmonary arterial hypertension therapy.

\section{Discussion}

Late-term mortality in patients who have undergone a Fontan operation is associated with progressive myocardial failure, dysrhythmia, and thromboembolism. The

Table III. Characteristics of Patients Who Underwent Catheterization.

\begin{tabular}{llll}
\hline $\begin{array}{l}\text { Patients who underwent catheterization after } \\
\text { Fontan }(\mathrm{n}=31 \%)\end{array}$ & Ratio (\%) & Age (years) & $\begin{array}{l}\text { PA pressure } \\
(\mathrm{mmHg})\end{array}$ \\
\hline Pulmonary artery stent alone & $5(16.1 \%)$ & $6.5 \pm 8.3(1-19)$ & $15.2 \pm 4.2(11-20)$ \\
Fenestration closure & $12(38.7 \%)$ & $6.5 \pm 2.4(3-10)$ & $12.6 \pm 1.9(10-15)$ \\
Pulmonary artery stent + fenestration closure & $5(16.1 \%)$ & $8.2 \pm 7.7(4-22)$ & $11.2 \pm 3.2(8-16)$ \\
Pulmonary antegrade closure & $3(9.7 \%)$ & $4.8 \pm 0.2(4.5-5)$ & $15.6 \pm 4.1(11-19)$ \\
Pulmonary artery stent + antegrade closure & $1(3.2 \%)$ & 4.5 & 13 \\
Fenestration opening & $5(16.1 \%)$ & $10.3 \pm 5.1(6-16)$ & $19.7 \pm 0.9(19-21)$ \\
\hline
\end{tabular}

PA, pulmonary artery. 
rate of morbidity during follow-up can reach up to $11 \%$, with causes including atrial dysrhythmia, protein losing-enteropathy, liver dysfunction, congestive heart failure, progressive ventricular dysfunction, and stroke. ${ }^{6}$ In such cases, atrioventricular valve failure, pulmonary venous obstruction, pulmonary artery stenosis, or high venous pressure due to obstruction of the Fontan baffle should be excluded, and Fontan fenestration should be investigated ${ }^{6}$ When needed, small fenestrations should be widened with a catheter, and patients should undergo balloon dilatation or stent implantation procedures. These procedures may improve cardiac output and increase arterial saturation. ${ }^{7}$ In the present patient group, a transcatheter procedure was performed in a total of $31(16.9 \%)$ patients in the first year after surgery.

Atrioventricular synchronization is necessary for optimal Fontan function. During long-term follow-up, arrhythmia contributes significantly to mortality among Fontan patients. ${ }^{7}$ In our patient group, seven $(3.8 \%)$ patients are still being followed-up for arrhythmia and are currently maintained in sinus rhythm under medical therapy.

Systolic dysfunction is characterized by a decrease in contraction functions and becomes a matter of concern when the ejection fraction drops below 50\%. ${ }^{6}$ Diastolic dysfunction, on the other hand, is harder to define. The ventricular relaxation rate and ventricular end-diastolic pressure increase in a heart with a decreased ejection fraction. ${ }^{6}$ In the present patient group, $15(8.2 \%)$ patients had systolic dysfunction, and the systemic ventricle was the left ventricle in the majority of those patients. During long-term follow up, systolic and diastolic dysfunctions persist in Fontan patients, affecting mortality and morbidity. The global causes of reductions in ventricular function include increased systemic vascular resistance after a Fontan operation, improper hypertrophy of the left ventricle due to an increased mass/volume ratio, high pulmonary vascular resistance, and univentricular anatomy. ${ }^{8}$ Following a Fontan operation, the rudimentary ventricle may play a significant role in impairing the global functions of the univentricular heart. ${ }^{9}$ In a study by Hui et al. ${ }^{9}$, regional myocardial performance was found to be significantly reduced in the rudimentary right ventricles of Fontan patients. The authors concluded that intra-univentricular diastolic asynchrony may further impair univentricular diastolic function and can play a significant role in global univentricular functions. Among our patients with systolic dysfunction, only two (13.4\%) developed systolic dysfunction in the biventricular structure, while the remaining $86.6 \%$ had a rudimentary ventricle.

Angiotensin converting enzyme inhibitors were observed to reduce mortality and morbidity among adult patients with asymptomatic left ventricular dysfunction. ${ }^{7}$ On the other hand, a decrease in the afterload without preserving the preload in Fontan patients does not result in increased cardiac output, and may prove harmful by causing hypotension. ${ }^{7}$ The role of low-dose afterload reducers remains unclear in terms of their regulation of diastolic functions, and therefore the benefits of angiotensin converting enzyme inhibitors after Fontan could not be demonstrated. ${ }^{8}$ Spironolactone, on the other hand, appears to be a good treatment option for patients with an insufficient Fontan physiology, although it is a weak diuretic and should be used in combination with loop diuretics. ${ }^{6}$ By reducing oxygen consumption, up-regulating beta adrenergic receptors, producing antiarrhythmic effects, reducing cardiac norepinephrine, and improving ventricular diastolic functions, beta-blockers prolong survival and improve cardiac function in adult patients with chronic heart failure. ${ }^{10}$ Carvedilol is a potent non-selective betablocker that induces vasodilatation and exerts antioxidant effects by causing al adrenergic receptor blockage, and is thus considered the primary treatment option for chronic heart failure. ${ }^{11}$ Levels of phosphodiesterase 5 were found to be elevated in the myocardium of stressed ventricles, and Fontan patients with chronic heart failure arising from systemic ventricular dysfunction can benefit from these treatments. ${ }^{10}$ However, additional studies are needed to observe potential improvements in ventricular function in Fontan patients undergoing such therapies. In the present study, patients were started on angiotensin converting enzyme inhibitors, furosemide, and acetylsalicylic acid treatments after the operation, and catheterization was later 
performed in the event of the development of ventricular dysfunction; medical therapies were provided when no anatomical problem was detected.

In their study, including a 20-year followup, of Fontan patients, Ono et al. ${ }^{1}$, carried out reoperations in $81.7 \%$ of patients, and performed catheterization procedures in $29.7 \%$ (fenestration closure, stent implantation, balloon angioplasty, collateral closure). Systemic ventricular function was found to be decreased (ejection fraction $<50 \%$ ) in $11.8 \%$ of their patients, and whether the ventricular structure of the systemic ventricle was right or left made no significant difference to systemic ventricular functions. The authors concluded that the early removal of volume load preserved longterm ventricular function, and they performed a Glenn procedure in the $3^{\text {rd }}$ month and an extracardiac total cava pulmonary connection in the $18^{\text {th }}$ month. Based on their findings, the early Glenn intervention preserved long-term ventricular function by providing protection against ventricle hypertrophy, subendocardial ischemia, and diastolic dysfunction. The systemic right ventricle was not found to be a risk factor for mortality but only for prolonged hospital stay, late re-intervention, and protein losing-enteropathy. ${ }^{1}$

In another study, performed by the Mayo Clinic and involving 367 patients (71\% of whom had undergone an atriopulmonary Fontan), the most common causes of hospitalization during follow-up were arrhythmia and heart failure, noted in $22 \%$ and $20 \%$ of patients, respectively. The most common findings related to mortality were cardiac surgeries $(11 \%)$ and heart failure (8\%). ${ }^{12}$ The authors concluded that the treatment of arrhythmia and heart failure could have improved the outcomes in their patient group.

Death due to heart failure is uncommon in the first 10 years following a Fontan operation. In a study of 546 children, abnormal ventricular ejection fraction and diastolic dysfunction were observed in $27 \%$ and $72 \%$ of patients, respectively. Patients who underwent a ventriculotomy were found to be at risk, and the authors concluded that early term chronic hypoxemia and ventricular volume load contributed to late-term failure in cases of univentricular heart. ${ }^{13}$

To demonstrate and treat problems arising from the Fontan procedure, catheterization is required during postoperative follow-up in a considerable proportion of patients who undergo a Fontan operation. Even if the systemic ventricle is in the left ventricular structure, systolic dysfunction in the systemic ventricle develops, especially after the first 10 years, and rudimentary ventricle function should also be carefully monitored for intrauniventricular diastolic asynchrony.

\section{REFERENCES}

1. Ono M, Kasnar-Samprec J, Hager A, et al. Clinical outcome following total cavopulmonary connection: A 20-year single-centre experience. Eur J Cardiothorac Surg 2016; 50: 632-641.

2. Bristow MR. Beta-adrenergic receptor blockade in chronic heart failure. Circulation 2000; 101: 558-569.

3. Marcelletti CF, Hanley FL, Mavroudis C, et al. Revision of previous Fontan connections to total extracardiac cavopulmonary anastomosis: a multicenter experience. J Thorac Cardiovasc Surg 2000; 119: 340-346.

4. Goff DA, Blume ED, Gauvreau K, Mayer JE, Lock JE, Jenkins KJ. Clinical outcome of fenestrated Fontan patients after closure: the first 10 years. Circulation 2000; 102: 2094-2099.

5. Kutty S, Rathod RH, Danford DA, Celermajer DS Role of imaging in the evaluation of single ventricle with the Fontan palliation. Heart 2016; 102: 174-183.

6. Ghanayem NS, Berger S, Tweddell JS. Medical management of the failing Fontan. Pediatr Cardiol 2007; 28: 465-471.

7. Pfeffer MA, Braunwald E, Moyé LA, et al. Effect of captopril on mortality and morbidity in patients with left ventricular dysfunction after myocardial infarction. Results of the survival and ventricular enlargement trial. The SAVE Investigators. N Engl J Med 1992; 327: 669-677.

8. Gewillig M, Goldberg DJ. Failure of the fontan circulation. Heart Fail Clin 2014; 10: 105-116.

9. Hui W, Abd El Rahman MY, Schuck R, et al. Diastolic asynchrony and myocardial dysfunction in patients with univentricular heart after Fontan operation. J Echocardiogr 2013; 11: 130-137.

10. Goldberg DJ, Shaddy RE, Ravishankar C, Rychik J. The failing Fontan: etiology, diagnosis and management. Expert Rev Cardiovasc Ther 2011; 9: 785-793. 
11. Waagstein F, Hjalmarson A, Varnauskas E, Wallentin I. Effect of chronic beta-adrenergic receptor-blockade in congestive cardiomyopathy. Br Heart J 1975; 37: 1022-1036

12. Egbe A, Khan AR, Al-Otaibi M, Said SM, Connolly HM. Outcomes of hospitalization in adults with Fontan palliation: The Mayo Clinic experience. Am Heart J 2018; 198: 115-122.
13. Mondésert B, Marcotte F, Mongeon FP, et al. Fontan circulation: success or failure? Can J Cardiol 2013; 29: 811-820. 